(2) Open Access Full Text Article

\title{
Intraocular lens intracapsular fixation with unilateral loop suture for 180 degree Zinn's zonule dialysis
}

This article was published in the following Dove Press journal:

Clinical Ophthalmology

\section{Yukihiko Suzuki \\ Kobu Adachi \\ Yoshihiro Jinnai \\ Kaori Suzuki \\ Mitsuru Nakazawa}

Department of Ophthalmology,

Hirosaki University Graduate School of Medicine, Hirosaki, Aomori, Japan
Correspondence: Yukihiko Suzuki

Department of Ophthalmology, Hirosaki

University Graduate School of Medicine,

5 Zaifu, Hirosaki 036-8562, Japan

Tel +8I I7 2395095

Fax +8I I7 2375735

Email yukihiko@hirosaki-u.ac.jp

\begin{abstract}
We developed intraocular lens (IOL) fixation procedure that only uses one suture during Zinn's zonule dialysis portion of the combined surgery for IOL intracapsular fixation and unilateral loop suture for preserving the lens capsule. We treated 15 eyes in 15 patients which were confirmed to have almost $180^{\circ}$ zonular dialysis during cataract surgery. After removing the lens, a scleral flap was created on the dialysis side. A straight needle for suturing was then inserted into the anterior chamber from the opposite side of the dialysis. The needle was used to attach the equatorial segment of the capsule on the dialysis side from the inside to the outside and then pull the suture thread under the scleral flap. After the thread was bound to a preceding loop of IOL, the IOL was inserted into the bag. Our procedure was found to be simple and less invasive, as our technique required no vitrectomy to be performed.
\end{abstract}

Keywords: intraocular lens, zonular dialysis, IOL scleral suturing, cataract surgery

\section{Plain language summary}

For Zinn's zonule dialysis extending over a range of $180^{\circ}$, IOL intracapsular fixation using a Cionni ring is performed in some institutions. However, this procedure requires preparation of the ring in advance and is technically difficult. In another procedure, an IOL is fixed with sutures after completely removing the lens capsule. This is complicated, as it requires performance of a vitrectomy. The present procedure for Zinn's zonule dialysis is considered to be simple, with no vitrectomy or special instruments required. With it, an IOL is inserted into the lens capsule and only the IOL loop at the dialysis portion is sutured, thus preserving the lens capsule.

\section{Introduction}

When treating Zinn's zonule dialysis that extends over a range of $90^{\circ}$ to $180^{\circ}$, there are only a limited number of institutions that can perform intraocular lens (IOL) intracapsular fixation using a Cionni ring to fix the dialyzed capsular bag on the sclera while stabilizing it. ${ }^{1-6}$ On the other hand, most institutions can and do utilize a technique that was initially reported by Malbran et $\mathrm{al}^{7}$ in 1986 for suturing the IOL after completely removing the capsular bag. After Lewis reported a new transscleral suture technique ${ }^{8}$ that is performed from the opposite side, several different less invasive methods have been implemented, such as the use of a foldable IOL through a small incision and sutureless intrascleral posterior chamber IOL fixation. ${ }^{9-13}$

In the current study, we describe a less invasive technique for partial IOL suturing in patients with extensive Zinn's zonule dialysis that uses only the dialysis portion while preserving the capsular bag (combined procedure of IOL intracapsular fixation 
and unilateral loop suture). We also report clinical results obtained after using this technique.

\section{Surgical technique}

First, as the capsular bag collapses on the dialysis side, it is re-inflated with a viscoelastic material (Figures 1A and 2A). After creating a sclera flap in the same direction as the dialysis, a $27 \mathrm{G}$ needle is inserted under the flap at the point of 1.5-2.0 mm from corneal limbus (Figure 1B). A straight Pair-Pak ${ }^{\mathrm{TM}}$ needle (Alcon, Hünenberg, Switzerland) is used for suturing the IOL and inserted from the opposite side to perform transscleral suturing. After using the $27 \mathrm{G}$ and Pair-Pak needles to pierce through the outside and inside, respectively, they are then pushed through the equatorial segment of the lens capsule of the dialysis portion. When the straight needle passes through the path of the $27 \mathrm{G}$ needle, it pierces the equatorial segment (Figures 1C and 2B). While maintaining the Pair-Pak needle within the $27 \mathrm{G}$ needle path, the $27 \mathrm{G}$ needle is pulled out from the scleral flap side (Figure 1D). Once the Pair-Pak needle and 10-0 polypropylene thread are drawn out of the sclerocorneal wound, it is cut and bound to the IOL loop with a reef knot. Next, the
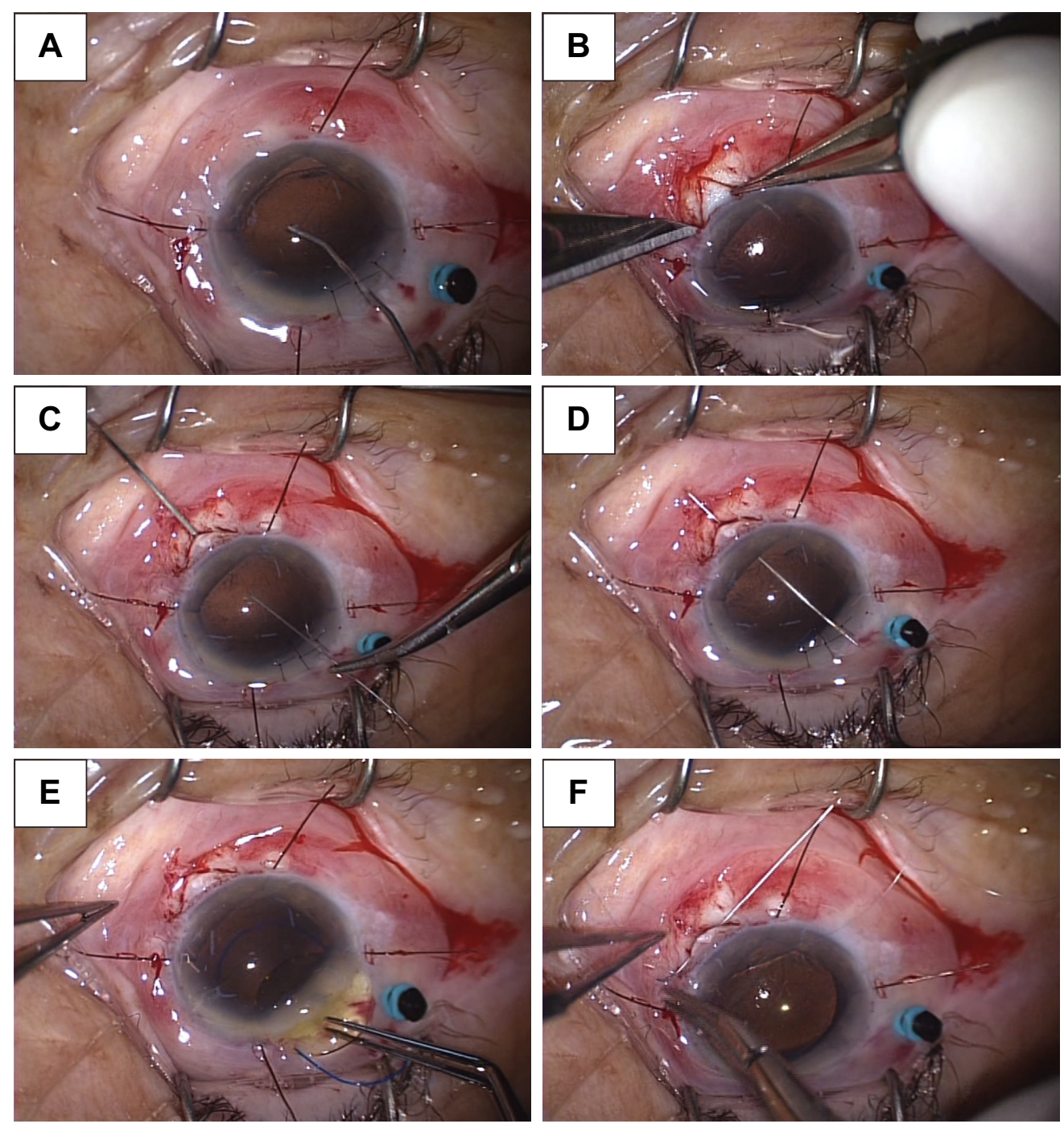

Figure I Surgical manipulations in Case I.

Notes: PEA was performed by widening the pupil with iris retractors. After confirming that the Zinn's zonule dialysis ranged from the 2 to 8 o'clock position, we removed the remaining lens nucleus by visco-extraction with a Simcoe aspiration needle. The procedure performed after the aspiration was as follows. (A) Viscoelastic material was packed into the collapsed capsular bag in the dialysis portion to re-inflate it to nearly normal. (B) A scleral flap was created at the 5 o'clock position. (C) A 27G needle was inserted under the scleral flap. A Pair-Pak ${ }^{\circledR}$ needle was inserted from the opposite side in order to pierce through the equatorial segment of the capsular bag. (D) The Pair-Pak needle was pushed from the interior of the eye to outside the sclera. (E) The preceding IOL loop was bound to the thread of the Pair-Pak needle that was inserted into the interior of the eye. (F) After inserting the posterior loop into the capsular bag, the thread of the preceding loop was sutured inside the scleral flap.

Abbreviations: IOL, intraocular lens; PEA, phacoemulsification and aspiration. 
thread on the opposite side is removed. When the dialysis is located inferiorly, the IOL loop with the thread is carefully inserted into the capsular bag. The optical part is inserted into the bag, and a posterior loop is carefully formed so as not to exert stress. Upon completion, intracapsular fixation of the IOL as a whole is achieved (Figure 1E). The thread bound to the preceding loop is then drawn with enough tension to keep the IOL centered and sutured to the sclera (Figures $1 \mathrm{~F}$ and $2 \mathrm{C}$ ). The surgery is completed by suturing the scleral flap onto the loop.

An NX-70 (Santen, Osaka, Japan) three-piece IOL with an optical diameter of $7.0 \mathrm{~mm}$ was used in 14 patients. Use of this IOL ensured stability of the in-the-bag fixation, as there is less incidence of failing vision even in the unlikely event of slight deflection of the IOL.
As the sutures are tightened, the IOL haptics will shift toward inner scleral wall and thus possibly makes the optic decenter. Large IOL optics of $7 \mathrm{~mm}$ may hinder the problem, but surgeons should take care not to suture the thread tightly.

\section{Cases}

Case 1 was an 81-year-old woman who had a right glaucomatous attack 1 day before surgery. The day after undergoing instillation therapy, her IOP decreased from 60 to $32 \mathrm{mmHg}$ (Figure 3A and B). Phacoemulsification and aspiration (PEA) with IOL implantation (PEA+ IOL) was planned in order to address a persistent shallow anterior chamber. Preoperative visual acuity of her right eye was 20/200, and while performing preliminary cored vitrectomy to reduce
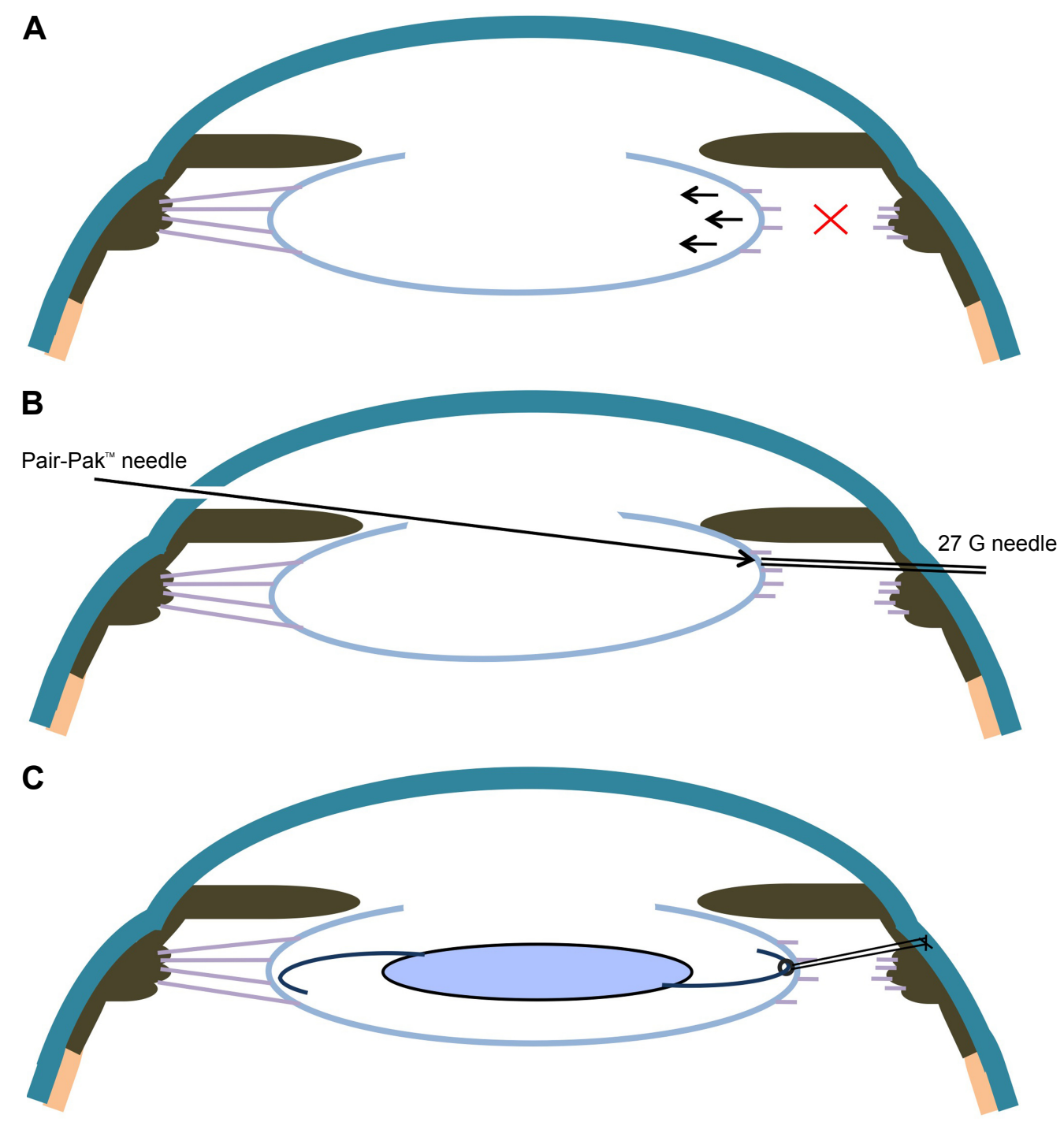

Figure 2 (A) Zinn's zonule dialysis is observed in the right side. (B) The straight needle of Pair-Pak passes through the path of the $27 \mathrm{G}$ needle, it pierces the equatoria segment. (C) At the end of the surgery, the unilateral IOL loop is fixed with a 10-0 polypropylene thread from the scleral flap.

Abbreviation: IOL, intraocular lens. 

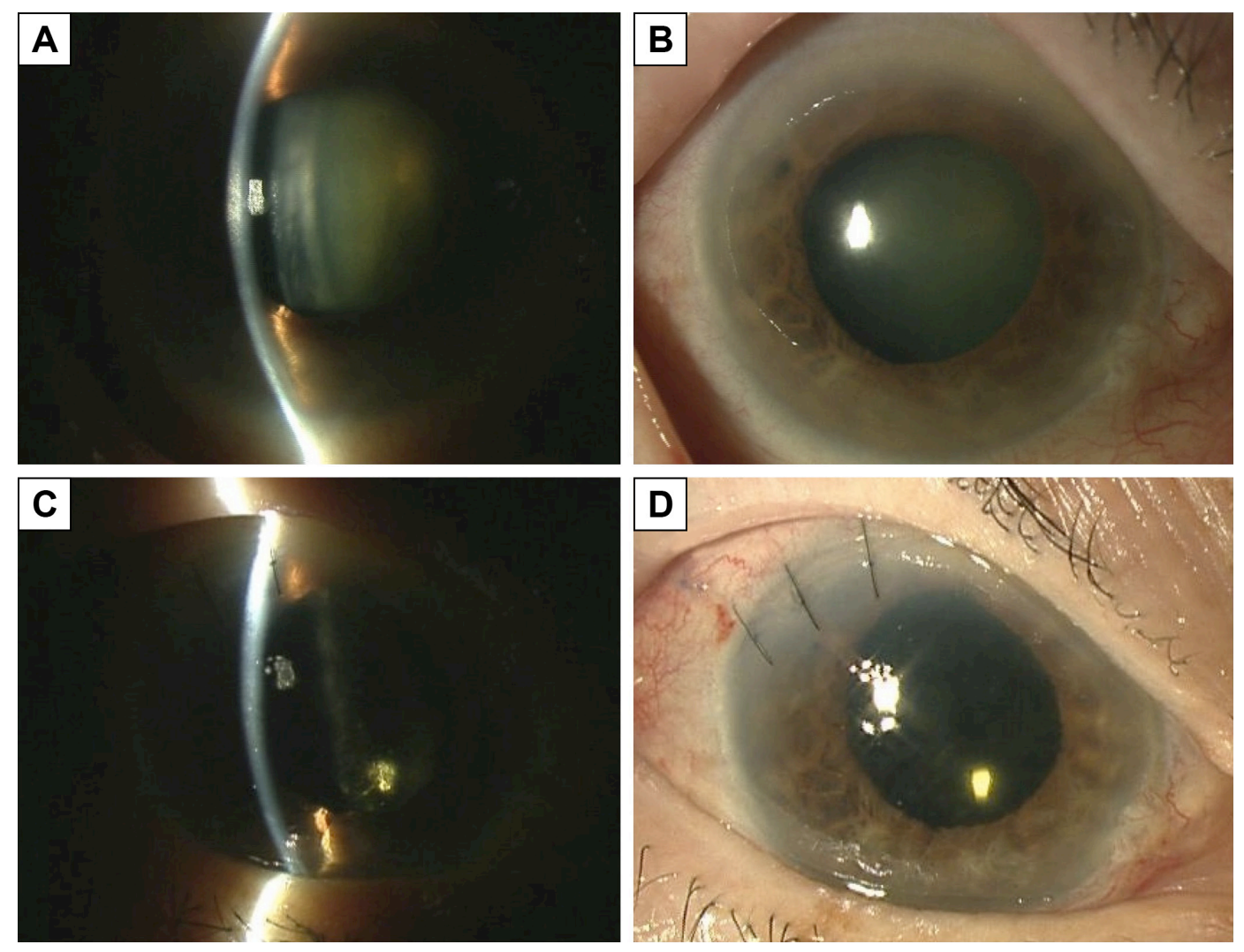

Figure 3 Case I: Preoperative anterior segment of the right eye.

Notes: (A) A cataract and shallow anterior chamber were observed. (B) Moderate mydriasis was observed. (C), (D) Anterior segment of the right eye at I week after the operation. The anterior chamber was deep and did not exhibit any IOL inclination or deflection. The pupil was nearly circular.

Abbreviation: IOL, intraocular lens.

the IOP and PEA with iris retractors attached for treating poor mydriasis, we confirmed that there was extensive Zinn's zonule dialysis. Because of this, PEA was abandoned. After enlarging the sclerocorneal incision, the lens nucleus was extracted by the visco-extraction technique, with the remaining cortex then carefully removed by perfusion using a Simcoe aspiration cannula. As Zinn's zonule dialysis ranged from the 2 to 8 o'clock position of the capsular bag, IOL intracapsular insertion with an ordinary procedure was considered impossible. Thus, IOL fixation was performed by suturing the unilateral loop to the scleral flap that had been created at the 5 o'clock position via the use of a thread inserted from the opposite side (Figure 3). At 15 months after the operation, visual acuity of her right eye had recovered to 20/22 and the IOP was $7 \mathrm{mmHg}$. Furthermore, no dislocation of the IOL was observed in the patient.

Case 2 was a 66-year-old man with an ocular contusion that had developed over a few years prior to being examined by us. The right eye had a mature cataract. Preoperative visual acuity was hand motion and IOP was $18 \mathrm{mmHg}$. Initial surgical plans included performing PEA+IOL for the right eye. However, as extensive dialysis of Zinn's zonule developed during the PEA, the surgical wound was enlarged to remove the remaining lens nuclear strips by visco-extraction followed by extraction of the cortex using a Simcoe aspiration cannula. After confirming that the dialysis position ranged from just before the 5 o'clock to just before 11 o'clock position, a scleral flap was created at just before the 7 o'clock position. Afterwards, a Pair-Pak needle was then inserted from the opposite side. In order to insert the loop into the capsular bag, the thread was bound to the preceding loop of the IOL, with the posterior loop inserted as it was into the bag. The thread of the preceding loop was then sutured to the sclera. At 19 months after the surgery, right visual acuity was 20/30 and IOP was $17 \mathrm{mmHg}$. There were no complications observed.

In Table 1, patient age and sex, affected eye (right or left), preoperative eye condition, preoperative visual acuity, intraoperative condition, such as range of Zinn's zonule dialysis, site of IOL loop suture, type of IOL used, postoperative visual acuity, and complications are shown for Cases 3-15. In all the 15 eyes, glaucoma attack, phacodonesis, and lens subluxation were frequently seen prior to surgery. As for 
Table I Preoperative, intraoperative, and postoperative states in cases treated with this procedure

\begin{tabular}{|c|c|c|c|}
\hline Case & Preoperative states & Intraoperative states & Postoperative states \\
\hline Age/sex/eye & Ocular condition/Va/Zonular dialysis & Additional procedure/Scleral flap/IOL & $\begin{array}{l}\text { Va/Refraction/Observation duration/ } \\
\text { Complications }\end{array}$ \\
\hline I. $8 \mathrm{I} / \mathrm{F} / \mathrm{R}$ & Glaucoma attack/20/200/2-8 o'clock & Cored vitrectomy*/5 o'clock/NX-70 & $20 / 22 / S+0.75$ C- $2.0125^{\circ} / 21$ months/none \\
\hline 2. $66 / M / R$ & Mature cataract/HM/4-10 o'clock & Convert to ECCE/7 o'clock/NX-70 & $20 / 30 / \mathrm{S}+1.75 \mathrm{C}-1.090^{\circ} / 19$ months/none \\
\hline 3. $81 / M / R$ & PE, glaucoma attack/20//00/8-2 o'clock & None/II o'clock/NX-70 & 20/20/S-2.25 C- $0.5125^{\circ} / 19$ months/none \\
\hline 4. $64 / \mathrm{M} / \mathrm{L}$ & Lens subluxation/20/60/9-3 o'clock & None/I 2 o'clock/NX-70 & $20 / 16 / \mathrm{S}-4.0 \mathrm{C}-1.25 \mathrm{I} 50^{\circ} / 13$ months/none \\
\hline 5. $88 / \mathrm{F} / \mathrm{L}$ & Glaucoma attack/HM/3-10 o'clock & Cored vitrectomy*/7 o'clock/NX-70 & $20 / 60 / \mathrm{S}-2.25 \mathrm{C}-1.75150^{\circ} / 24$ months/none \\
\hline 6. $84 / F / R$ & PACG, LI/HM/3-9 o'clock & Convert to ECCE/6 o'clock/NX-70 & $20 / 60 / \mathrm{S}-1.25 \mathrm{C}-\mathrm{I} .5$ 5\%/5 months/none \\
\hline 7. $76 \mathrm{M} / \mathrm{L}$ & Mature cataract/LP/2-8 o'clock & Convert to ECCE/5 o'clock/NX-70 & $20 / 200 / \mathrm{S}+\mathrm{I} .0 \mathrm{C}-2.2595^{\circ} / 5$ months/none \\
\hline 8. $88 / F / L$ & PAC, LI/4/200/I-6 o'clock & None/4 o'clock/PN6A & $\begin{array}{l}20 / 200 / \mathrm{S}+2.5 \mathrm{C}-4.75 / 110^{\circ} / 6 \text { months/ } \\
\text { capsular bag contraction }\end{array}$ \\
\hline 9. $8 \mathrm{I} / \mathrm{F} / \mathrm{R}$ & Phacodonesis/20/500/2-8 o'clock & Convert to ECCE/4 o'clock/NX-70 & $20 / 30 / S+6.0 \mathrm{C}-2.2570^{\circ} / 5$ months/none \\
\hline 10. 84/F/L & Glaucoma attack/CF/I0-5 o'clock & None/l o'clock/NX-70 & $\begin{array}{l}\text { 20/60/S- } 0.25 \text { C- } 0.7510^{\circ} / 4 \text { months/ } \\
\text { after cataract }\end{array}$ \\
\hline II. 89/F/L & PE, phacodonesis/HM/I0-2 o'clock & None/I2 o'clock/NX-70 & $20 / 100 / \mathrm{S}-4.5$ C- $0.7530^{\circ} / 4$ months/none \\
\hline I2. 85/F/L & $\begin{array}{l}\text { PACG, phacodonesis/20/I,000/ } \\
\text { I2-6 o'clock }\end{array}$ & None/3 o'clock/NX-70 & $20 / 50 / \mathrm{S} \pm 0.0 \mathrm{C}-1.080^{\circ} / \mathrm{I}$ months/none \\
\hline 13. $57 / \mathrm{M} / \mathrm{L}$ & $\begin{array}{l}\text { Traumatic cataract, phacodonesis, corneal } \\
\text { laceration/HM/6-12 o'clock }\end{array}$ & $\begin{array}{l}\text { Suture of corneal wound/9 o'clock/ } \\
\text { NX-70 }\end{array}$ & $\begin{array}{l}20 / 24 / \mathrm{S} \pm 0.0 \mathrm{C}-4.0 \quad 120^{\circ} / 3 \text { months/ } \\
\text { corneal opacity }\end{array}$ \\
\hline 14. 58/F/L & Glaucoma attack/20/I00/I-6 o'clock & Cored vitrectomy*/3 o'clock/NX-70 & $\begin{array}{l}20 / 16 / \mathrm{S}-0.5 \mathrm{C}-2.5175^{\circ} / 3 \text { months/ } \\
\text { tilted pupil }\end{array}$ \\
\hline I5. $72 / F / R$ & Phacolytic glaucoma/LP/I0-2 o'clock & None/I2 o'clock/NX-70 & $\begin{array}{l}\text { 20/20/S- } 0.75 \text { C- } 0.5130 \% / 3 \text { months/ } \\
\text { posterior synechia }\end{array}$ \\
\hline
\end{tabular}

Notes: Cored vitrectomy*, preliminary performed cored vitrectomy to reduce the intraocular pressure. NX-70, Three-piece $1 \mathrm{OL}$ with optic diameter $7 \mathrm{~mm}$ (by Santen, Osaka, Japan). PN6A, Three-piece IOL with optic diameter 6mm (by Kowa, Nagoya, Japan).

Abbreviations: ECCE, extra-capsular cataract extraction; F, female; LI, history of laser iridotomy; IOL, intraocular lens; M, male; PACG, primary angle closure glaucoma; $\mathrm{PE}$, pseudoexfoliation; L, left; $\mathrm{R}$, right.

postoperative complications, lens capsule contraction was seen in one and tilted pupil occurred in one eye and partial posterior synechia in one eye, while no other severe complications were noted.

\section{Ethic approval and informed consent}

This research has received ethic approval from The Research Ethics Committee in Hirosaki University Graduate School of Medicine. The research adhered to the tenets of the Declaration of Helsinki. Written informed consents were obtained from the patients for publication of this case series report and any accompanying images.

\section{Discussion}

Surgical treatment for Zinn's zonule dialysis is generally performed when patients have traumatic lens subluxation, a very fragile zonule, or an unexpected complication that occurs during PEA. Non-traumatic lens subluxation or very fragile zonule occurred for unknown reasons or complicated with psuedoexfoliation syndrome, Marfan syndrome, Marchesani sundrome, homocystiuria, Stickler syndrome, and others. ${ }^{14}$

For Zinn's zonule dialysis in a narrow range up to $90^{\circ}$, an IOL is normally inserted into the capsular bag and the IOL loop is fixed in order to stretch the bag on the dialysis side with a unilateral loop and prevent retraction of the capsular bag in the dialysis portion toward the center. When the Zinn's zonule dialysis ranges from $90^{\circ}$ to $180^{\circ}$, the capsular bag can be fixed by suturing it to the ciliary sulcus with a thread, while stretching the bag in the dialysis portion with a Cionni ring. ${ }^{1-6}$ This has proved to be a good technique for obtaining stable IOL fixation and overcoming the disadvantage of the Zinn's zonule dialysis while inserting the IOL into the capsular bag. However, since it is necessary to prepare the proper instruments in advance, it cannot be readily performed at all institutions when cases of dialysis unexpectedly develop as a surgical complication. On the other hand, there are other techniques for suturing the IOL to the ciliary sulcus after removing the capsular bag and the anterior vitreous. These techniques can be performed in 
cases where the intracapsular fixation has been abandoned. However, even in these cases, it is necessary to prepare the same instruments used for vitreous surgery and suture the IOL at two sites as usual. Unfortunately, this technique is complicated and can take considerable time, thereby extend surgery duration. Moreover, it is necessary to observe the patient postoperatively for unstable fixation, such as IOL inclination. ${ }^{15,16}$

We believe that the present technique will make it possible to fix the IOL under more idealistic physiological conditions and avoid the aforementioned problems, as no special preparations are necessary and the surgery can be completed within a relatively short period. With regard to the 10-0 polypropylene thread of the Pair-Pak needle that is passed through the equatorial segment of the capsular bag, care must be taken to strongly pull the thread or else the bag will be easily broken by the thread. Since Zinn's zonule can be widely attached to the equatorial segment, this makes the dialysis avoid to extend compared with other parts. Furthermore, this technique uses a slightly anterior position for fixation of the loop, through which the thread is drawn as a result of in-the-bag fixation with a usual single loop and in-the-bag fixation. This combined with our use of the ciliary sulcus from the other side means that the fixation can be completed without deflection toward the direction of the suture or anterior inclination. We were able to obtain this result because we took the balance of the tension of Zinn's zonule on the opposite side into consideration and did not pull too strongly on the Pair-Pak thread.

There is also the question of whether suturing is adequate for the dialysis portion only and whether the dialysis portion will be likely to enlarge and cause the IOL to dislocate in cases with a weak Zinn's zonule. While we believe that the dialysis area could indeed enlarge if the IOL continues to keep moving, since our technique makes it possible to fix the IOL so that it is more similar to the actual physiological state in the capsular bag, this should control IOL-donesis and prevent dislocation.

For cases where there is an extremely fragile Zinn's zonule or a risk of IOL luxation when only using intracapsular fixation, a new technique has been developed in which the IOL is fixed in the capsular bag by suturing the bilateral loops with a 9-0 polypropylene thread (PC-9 ${ }^{\circledR}$, Alcon). ${ }^{17}$ When using this technique, it has been found that IOL inclination and other problems were less frequent for the in-the-bag suturing group vs the out-of-the-bag group. When using this technique, however, it is likely that the angle of the thread passing through the lens capsule and the angle passing though the ciliary sulcus will not match. This is because the method requires a curved needle threaded with 9-0 polypropylene thread first be inserted from the sclerocorneal incision wound and moved crosswise in order to pierce the equatorial segment of the capsular bag before it is further inserted crosswise into the ciliary sulcus. With our technique, a straight Pair-Pak needle is inserted from the opposite side of the suture and used to cross the equatorial segment and ciliary sulcus. As a result, it is less likely that the site of needle insertion in the capsular bag and that in the ciliary sulcus will deviate. Furthermore, it is considered unlikely that there will be capsular bag breakage when using our method. Although 10-0 polypropylene is easy to manipulate and has plus side in terms of availability, it is notorious for suture breakage ${ }^{9}$ over time and this needs to be discussed.

In conclusion, we propose that the present technique is an optional treatment that can be used to fix an IOL in a manner that closely simulates the actual physiological intracapsular fixation. This technique can be performed within a relatively short period and without the use of special instruments in patients with sudden Zinn's zonule dialysis with potential surgical complications. However, this surgery should be performed by an experienced surgeon.

\section{Author contributions}

All authors contributed toward data analysis, drafting and critically revising the paper and agree to be accountable for all aspects of the work.

\section{Disclosure}

The authors have no financial interests to disclose and report no other conflicts of interests in this work.

\section{References}

1. Cionni RJ, Osher RH. Management of profound zonular dialysis or weakness with a new endocapsular ring designed for scleral fixation. $J$ Cataract Refract Surg. 1998;24(10):1299-1306.

2. Moreno-Montañés J, Sainz C, Maldonado MJ. Intraoperative and postoperative complications of Cionni endocapsular ring implantation. J Cataract Refract Surg. 2003;29(3):492-497.

3. Menapace R, Findl O, Georgopoulos M, Rainer G, Vass C, Schmetterer K. The capsular tension ring: designs, applications, and techniques. J Cataract Refract Surg. 2000;26(6):898-912.

4. Cionni RJ, Osher RH, Marques DM, Marques FF, Snyder ME, Shapiro S. Modified capsular tension ring for patients with congenital loss of zonular support. J Cataract Refract Surg. 2003;29(9):1668-1673.

5. Por YM, Lavin MJ. Techniques of intraocular lens suspension in the absence of capsular/zonular support. Surv Ophthalmol. 2005;50(5): 429-462. 
6. Vasavada AR, Praveen MR, Vasavada VA, et al. Cionni ring and in-thebag intraocular lens implantation for subluxated lenses: a prospective case series. Am J Ophthalmol. 2012;153(6):1144-1153.

7. Malbran ES, Malbran E, Negri I. Lens guide suture for transport and fixation in secondary IOL implantation after intracapsular extraction. Int Ophthalmol. 1986;9(2-3):151-160.

8. Lewis JS. Ab externo sulcus fixation. Ophthalmic Surg. 1991;22(11): 692-695.

9. Yaguchi S, Yaguchi S, Noda Y, Taguchi Y, Negishi K, Tsubota K. Foldable acrylic intraocular lens with distended haptics for transscleral fixation. J Cataract Refract Surg. 2009;35(12):2047-2050.

10. Gabor SG, Pavlidis MM. Sutureless intrascleral posterior chamber intraocular lens fixation. J Cataract Refract Surg. 2007;33(11): 1851-1854.

11. Agarwal A, Kumar DA, Jacob S, et al. Fibrin glue-assisted sutureless posterior chamber intraocular lens implantation in eyes with deficient posterior capsules. J Cataract Refract Surg. 2008;34(9):1433-1438.

12. Rodríguez-Agirretxe I, Acera-Osa A, Ubeda-Erviti M. Needle-guided intrascleral fixation of posterior chamber intraocular lens for aphakia correction. J Cataract Refract Surg. 2009;35(12):2051-2053.
13. Pacella E, Malvasi A, Tinelli A, et al. Stickler syndrome in PierreRobin sequence prenatal ultrasonographic diagnosis and postnatal therapy: two cases report. Eur Rev Med Pharmacol Sci. 2010;14(12): 1051-1054.

14. Bellucci R, Pucci V, Morselli S, Bonomi L. Secondary implantation of angle-supported anterior chamber and scleral-fixated posterior chamber intraocular lenses. J Cataract Refract Surg. 1996;22(2):247-252.

15. Durak A, Öner HF, Koçak N, Kaynak S. Tilt and decentration after primary and secondary transsclerally sutured posterior chamber intraocular lens implantation. J Cataract Refract Surg. 2001;27(2):227-232.

16. Hayashi K, Hirata A, Hayashi H. In-the-bag scleral suturing of intraocular lens in eyes with severe zonular dehiscence. Eye. 2012;26(1): 88-95.

17. Asadi R, Kheirkhah A. Long-term results of scleral fixation of posterior chamber intraocular lenses in children. Ophthalmology. 2008; 115(1):67-72.
Clinical Ophthalmology

\section{Publish your work in this journal}

Clinical Ophthalmology is an international, peer-reviewed journal covering all subspecialties within ophthalmology. Key topics include: Optometry; Visual science; Pharmacology and drug therapy in eye diseases; Basic Sciences; Primary and Secondary eye care; Patient Safety and Quality of Care Improvements. This journal is indexed on

Submit your manuscript here: http://www.dovepress.com/clinical-ophthalmology-journal

\section{Dovepress}

PubMed Central and CAS, and is the official journal of The Society of Clinical Ophthalmology (SCO). The manuscript management system is completely online and includes a very quick and fair peer-review system, which is all easy to use. Visit http://www.dovepress.com/ testimonials.php to read real quotes from published authors. 